\title{
Effect of asynchronous transfer and oestrogen administration on survival and development of porcine embryos
}

\author{
R. D. Geisert ${ }^{1}$, G. L. Morgan ${ }^{2}$, M. T. Zavy $^{3}$, R. M. Blair ${ }^{1}$, L. K. Gries ${ }^{1}$, \\ A. $\operatorname{Cox}^{1}$ and T. Yellin ${ }^{1}$ \\ 'Oklahoma Agricultural Experiment Station, ${ }^{2}$ Department of Veterinary Medicine and Surgery, \\ Oklahoma State University, Stillwater, OK 74078, USA; and ${ }^{3}$ US Department of Agriculture, \\ ARS, El Reno, OK 73036, USA
}

\begin{abstract}
Summary. Results indicate that recovery of embryos on Days 11 and 13 of pregnancy was reduced for Day 5 embryos transferred to recipients on Day 6 of their oestrous cycle and was greatly reduced when embryos were transferred to recipients on Day 7 of the cycle $(P<0.01)$. Administration of oestradiol-17 $\beta$ on Day 11 of the recipient's cycle did not appear to affect embryo development on Day 13.

Day 6 embryos transferred to recipients on Day 8 of the oestrous cycle deteriorated rapidly within $24 \mathrm{~h}$ of transfer; there was no recovery of embryos from the uterus after $36 \mathrm{~h}$.

Treatment of pregnant gilts with $1 \mathrm{mg}$ oestradiol- $17 \beta$ (i.v.) on Day 10.5 resulted in total embryonic loss by Day 23, but pregnancy rates of gilts treated with oestradiol-17 $\beta$ on Day 12 were similar to those of vehicle-treated gilts $(60.6$ vs. $71 \cdot 4 \%)$.
\end{abstract}

Keywords: embryo; oestrogen; uterus; pig

\section{Introduction}

Successful establishment of pregnancy and survival of early conceptuses in gilts are partly dependent on conceptus synthesis of oestrogen and rapid trophoblastic elongation on Day 12 of pregnancy (Bazer et al., 1986; Geisert et al., 1990). Although conceptus oestrogen synthesis or exogenous oestrogen prolongs luteal function in gilts (Dhindsa \& Dziuk, 1968; Frank et al., 1978; Geisert et al., 1987; van der Meulen et al., 1988), maintenance of progesterone secretion does not ensure the survival of all embryos in this litter-bearing species. Approximately $20-50 \%$ of the early embryos represented by corpora lutea on the ovaries are lost prior to Day 25 of gestation in pigs (see review, Pope \& First, 1985).

In some gilts, early embryonic loss may result from the diversity in morphological development of littermate embryos (Pope et al., 1982; Wilmut et al., 1985). Early embryonic loss could result from the ability of advanced embryos to synthesize oestrogen and expand rapidly within the uterine lumen before less developed littermates (Geisert et al., 1982; Pope, 1988; Xie et al., 1990).

Although data indicate that stage of embryo development within a litter may affect survival (Pope, 1988), the mechanism by which less developed embryos are lost during early pregnancy is unknown. Earlier production of oestrogen by more-developed littermate embryos could stimulate release of secretions into the uterine lumen which are detrimental to their less developed siblings (Morgan et al., 1987a; Pope, 1988; Xie et al., 1990). Stimulation of uterine secretion could affect less developed embryos by blocking their ability to undergo trophoblastic elongation (Morgan et al., 1987a) or inhibiting developmental events required for conceptus attachment to the uterine epithelial surface (Morgan et al., 1987b; Blair et al., 1991). A delay in blastocyst elongation, 
an intrinsic response regulated by individual embryo development (Geisert et al., 1982; Morgan et al., 1987a), may reduce endometrial surface area available for attachment, which could become restrictive at later stages of development (Wu et al., 1989). The present experiments evaluated the role of the uterine environment on early development of porcine embryos and their survival, as affected by altering normal synchrony through embryo transfer and exogenous oestrogen administration.

\section{Materials and Methods}

Animals. Sexually mature crossbred gilts of similar age (7-8 months) and weight $(100-130 \mathrm{~kg})$ and having exhibited at least 2 oestrous cycles of normal duration (18-22 days) were used in all experiments. Gilts were observed for oestrous behaviour twice a day (08:00 and 18:00 h) in the presence of intact boars. Day of oestrus onset was designated Day 0. Gilts were mated to fertile boars when first detected in oestrus and 12 and $24 \mathrm{~h}$ later.

Embryo transfer. Embryo transfer procedures were performed following induction of anaesthesia with a $5 \%$ solution of thiopentone sodium (Abbott Laboratories, North Chicago, IL, USA) and 1 litre oxygen/min. The reproductive tract of the donor gilt was exposed via midventral laparotomy. After isolation of the oviduct, a small incision was made into the lumen of the isthmus with a cutting needle, $1.0 \mathrm{~cm}$ from the utero-tubal junction. A modified polyvinyl catheter with 2 side ports cut $1.5 \mathrm{~cm}$ from the tip was inserted into the oviduct and gently threaded $3-4 \mathrm{~cm}$ into the lumen of the uterine horn. The uterine horn was clamped between finger and thumb $20 \mathrm{~cm}$ from the uterine body while $20 \mathrm{ml}$ of modified Dulbecco's phosphate-buffered saline (mDPBS; Sigma Chemical Co., St Louis, MO, USA) containing $1 \%(\mathrm{v} / \mathrm{v})$ fetal calf serum was infused into the lumen. The fluid was gently massaged down the horn and then back through the catheter into a sterile dish. Embryos were immediately identified under a binocular microscope and transferred to a dish containing short-term culture medium (mDPBS containing $10 \%(\mathrm{v} / \mathrm{v})$ fetal calf serum). Embryos were washed twice in short-term culture medium at room temperature before transfer to recipient gilts.

Recipient gilts were prepared for surgery as described previously. The tip of each uterine horn was exposed and an incision was made in the isthmus. Embryos were drawn into the tip of a sterile Pasteur pipette (siliconized and firepolished) in $0.5 \mathrm{ml}$ of medium. The tip was gently passed through the puncture wound and into the lumen of the uterine horn for at least $4.0 \mathrm{~cm}$, where the embryos were deposited. The laparotomy incision was closed routinely. Gilts undergoing surgical procedures were injected (i.m.) with 20000 iu procaine penicillin $\mathrm{G} / \mathrm{kg}$ body wt.

Experiment 1. The experiment was designed to determine whether advancement of uterine secretion by exogenous oestrogen on Day 11 affected the ability of embryos to elongate on Day 12; and the effect of 1 or 2 days of asynchrony on embryo survival to Day 11 and their subsequent elongation. Embryos were collected from donor gilts $(n=33)$ on Day 5 of pregnancy. An average of 12 (range 9-16) morphologically normal embryos (morulae and blastocysts) was transferred into recipient females. Recipient gilts $(n=33)$ were randomized and assigned to one of the following treatment groups: (1) synchronous $(n=6$ ), Day- 5 embryos transferred to recipients on Day 5 of the oestrous cycle; (2) asynchronous $+24 \mathrm{~h}(n=13)$, Day-5 embryos transferred to recipients on Day 6 of the oestrous cycle; (3) asynchronous $+48 \mathbf{h}(n=9)$ Day-5 embryos transferred to recipients on Day 7 of the oestrous cycle; and (4) asynchronous $+24 \mathrm{~h}$ oestradiol-17 $\beta$, same as treatment 2 , but recipients received an i.m. injection of $5 \mathrm{mg}$ oestradiol valerate (R. J. Legere \& Co., Scottsdale, AZ, USA) on Day 11 of the oestrous cycle $(n=5)$. Recipient gilts were unilaterally ovario-hysterectomized on Day 11, via midventral laparotomy as described by Morgan et al. (1987b). After removal, the excised uterine horn was flushed with $20 \mathrm{ml}$ of sterile saline $(9 \mathrm{~g} \mathrm{NaCl} / \mathrm{l})$ and examined for the presence of embryos. The diameter of each embryo was measured to estimate the approximate time of trophoblastic elongation in the remaining uterine horn. If embryos were present in the uterine flushing, the remaining horn was removed and flushed 12-48 $\mathrm{h}$ later according to the estimated time of trophoblastic elongation predicted from stage of embryo development in the first uterine horn, as described by Geisert et al. (1982). If no embryos were present after flushing on Day 11 , the intact uterine horn was removed $48 \mathrm{~h}$ later. Only recipients which contained embryos on Day 11 recejved oestrogen in treatment 4.

Experiment 2. Failure to recover the Day-5 embryos transferred to recipient gilts on Day 7 of the oestrous cycle in Expt 1 suggested that embryo mortality occurred shortly after transfer. To determine more clearly when embryo loss was taking place, Day- 6 embryos were surgically transferred into the uterine horns of either synchronous (Day 6 of oestrous cycle, $n=5$ ) or asynchronous $+48 \mathrm{~h}$ (Day 8 of oestrous cycle, $n=4$ ) recipient gilts as described for Expt 1 . Gilts were ovario-hysterectomized 24-36 h after embryo transfer. Each uterine horn was flushed with $20-40 \mathrm{ml}$ of sterile saline and embryos were evaluated with a binocular microscope.

Experiment 3. The experiment was designed to determine whether advancement in uterine secretion by oestrogen treatment on Day 10.5 affected embryo survival to Day 23 of pregnancy compared with gilts receiving oestrogen on Day 12 (after embryo elongation). Seventeen mated gilts were assigned randomly to receive either vehicle $(0.8 \mathrm{ml}$ ethanol and $0.5 \mathrm{ml}$ saline) on Day 10.5 of pregnancy, oestradiol- $17 \beta$ ( $1 \mathrm{mg}$ in $0.5 \mathrm{ml}$ ethanol and $0.5 \mathrm{ml}$ saline) on Day 10.5 or oestradiol-17 $\beta$ in vehicle on Day 12 of pregnancy. Injection was into an ear vein. Gilts treated with vehicle or 
oestradiol-17 3 on Day 10.5 were hemi-ovariohysterectomized $12 \mathrm{~h}$ after injection. Gilts treated with oestradiol-17 3 on Day 12 of pregnancy had been hemi-ovariohysterectomized on Day 11 and the uterine horn flushed with $20 \mathrm{ml}$ of sterile saline $(9 \mathrm{~g} \mathrm{NaCl} / \mathrm{l})$. Diameters and developmental stages of embryos were recorded, the uterine flushings centrifuged at $10000 \mathrm{~g}$ for $15 \mathrm{~min}$ at $4^{\circ} \mathrm{C}$ and the supernatants stored at $-70^{\circ} \mathrm{C}$ until analysed for calcium, protein and acid phosphatase activity (for methods, see Geisert et al., 1982). The remaining uterine horn was removed on Day 23 of pregnancy and the number of embryos was recorded.

Statistical analysis. Data were analysed by least-squares analysis of variance using the general linear models procedure of the Statistical Analysis System (Barr et al., 1979). Differences in embryonic survival in Expts 1, 2 and 3 were analysed by $\chi^{2}$ analysis. Effects of oestrogen on recoverable calcium, protein and acid phosphatase activity in uterine flushings on Day 11 in Expt 3 were analysed for treatment effects. Orthogonal contrasts of means were made for vehicle and oestradiol-17 $\beta$ administered on Day 12 vs. oestradiol-17 $\beta$ administered on Day $10 \cdot 5$, and vehicle vs. oestradiol-17 $\beta$ administered on Day 12.

\section{Results}

Experiment 1: effect of oestrogen and asynchrony on embryo loss and development on Days 11 and 13

Asynchronous transfer of embryos to a uterine environment $24 \mathrm{~h}$ before their development resulted in a nonsignificant reduction in embryo survival at Day 11 , but transfer of embryos to recipients $48 \mathrm{~h}$ more advanced than the donor female resulted in failure to recover any embryos on Day 11. Oestradiol-17 $\beta$ treatment of gravid recipient gilts on Day 11 did affect conceptus development to Day 13: 11 of 18 gilts $(61 \%)$ were pregnant on Day 11 after transfer of Day-5 embryos to Day-6 recipients (treatments 2 and 4) compared with 6 of 6 pregnant gilts when donor and recipient gilts were synchronous (treatment 1). Only the recipient gilts with embryos on Day 11 were used to evaluate effects of oestradiol-17 $\beta$ for treatment 4 . Oestradiol administration on Day 11 did not affect embryonic development and survival: all 5 of recipient gilts $+24 \mathrm{~h}$ and treated with oestradiol- $17 \beta$ and 5 of 6 vehicle-treated $+24 \mathrm{~h}$ recipient gilts had filamentous conceptuses on Day 13 of pregnancy. Conceptuses from one $+24 \mathrm{~h}$ vehicle-treated recipient were $2-6 \mathrm{~mm}$ in diameter when recovered on Day 13. None of the nine $+48 \mathrm{~h}$ recipients $(P<0.01)$ contained conceptuses in uterine flushings on Day 11 or Day 13.

\section{Experiment 2: effect of $\mathbf{4 8} \mathrm{h}$ of asynchrony on early embryo loss}

Transfer of embryos to an advanced $(+48 \mathrm{~h})$ uterine environment resulted in embryo degeneration within $36 \mathrm{~h}$ of transfer. Embryo recovery rates $24-36 \mathrm{~h}$ after transfer between synchronous Day-6 donor and recipient gilts were $10 / 12,11 / 12,8 / 9,4 / 6$ and $9 / 11(42 / 50,84 \%)$. In contrast, only $36.6 \%(15 / 41)$ of the embryos transferred to recipients in which the uterine environment was $48 \mathrm{~h}$ in advance of the donors were recovered. Individual embryo recovery from $+48 \mathrm{~h}$ recipients was $8 / 9$ and $7 / 12(24 \mathrm{~h}$ after transfer) and $0 / 9$ and $0 / 11$ (36 h after transfer). Although 15 embryos were recovered from two $+48 \mathrm{~h}$ recipient gilts $24 \mathrm{~h}$ after transfer, the embryos appeared to be undergoing degenerative changes (Fig. 1a) as indicated by cell disorganization and cytoplasmic darkening. Embryos were very adhesive and tended to stick to cell debris in the uterine flushings. Synchronous Day-6 embryos (Fig. 1b) had developed to expanded blastocysts by $24 \mathrm{~h}$ after transfer; some were still within the zona pellucida with clear evidence of the embryoblast, while others had completed hatching. Unfertilized ova were evident in uterine flushings from 2 synchronous recipient gilts (Fig. 1 b). The total number of viable embryos collected $24-36 \mathrm{~h}$ after transfer was greater $(P<0 \cdot 01)$ for synchronous $(38 / 50)$ than for $+48 \mathrm{~h}(0 / 41)$ recipient gilts.

\section{Experiment 3: effect of uterine advancement by oestrogen on embryo survival to Day 23}

Embryos were obtained from all gilts when the uterine horn was flushed on Day 11 of pregnancy. The number of corpora lutea (CL) and embryos was similar in the treatment groups (Table 1). Diameter of spherical blastocysts ranged from $2-10 \mathrm{~mm}$, most gilts containing blastocysts of 


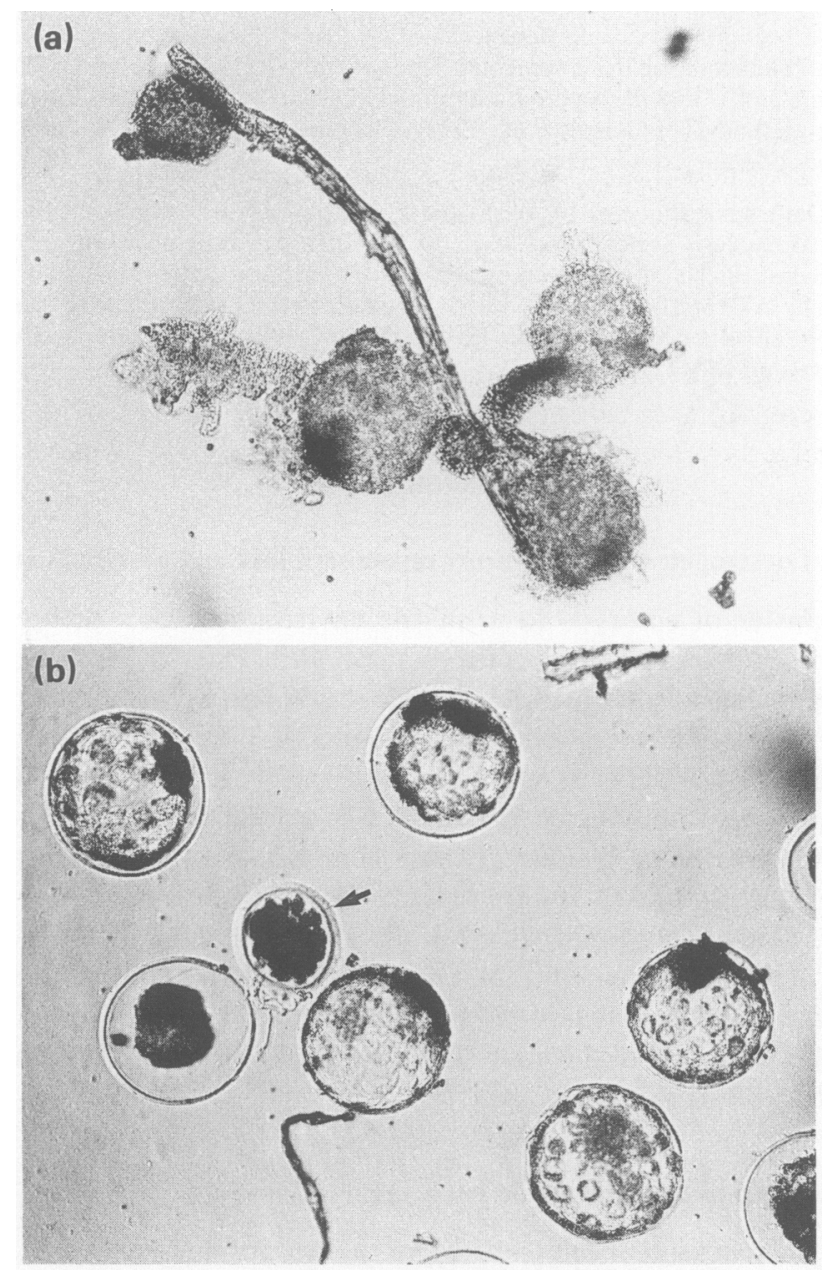

Fig. 1. Representative embryos recovered in uterine flushings from recipient gilts: (a) degenerative embryos collected $24 \mathrm{~h}$ after transfer to a recipient $48 \mathrm{~h}$ before donor female's cycle; (b) embryos collected from a synchronous recipient gilt $36 \mathrm{~h}$ after transfer. Note the presence of the recipients' unfertilized ova (arrow) and the thin zona pellucida surrounding the transferred blastocysts.

Table 1. Number of corpora lutea and embryos and total calcium, protein and acid phosphatase activity in uterine flushings from gilts on Day 11 of pregnancy

\begin{tabular}{|c|c|c|c|c|c|c|}
\hline Treatment & $n$ & $\begin{array}{l}\text { Number of } \\
\text { corpora } \\
\text { lutea }\end{array}$ & $\begin{array}{c}\text { Number of } \\
\text { embryos }\end{array}$ & $\begin{array}{c}\text { Calcium } \\
\text { (mg) }\end{array}$ & $\begin{array}{l}\text { Protein } \\
\text { (mg) }\end{array}$ & $\begin{array}{c}\text { Acid phosphatase } \\
\text { activity } \\
\text { ( } \mu \mathrm{mol} \mathrm{Pi} / \mathrm{min})\end{array}$ \\
\hline $\begin{array}{l}\text { Vehicle } \\
\text { Oestradiol-17B }\end{array}$ & 7 & $5 \cdot 3$ & $5 \cdot 0$ & $0.06^{2}$ & $15 \cdot 2$ & $11 \cdot 75^{\mathrm{c}}$ \\
\hline Day 10.5 & 5 & $7 \cdot 0$ & $7 \cdot 0$ & $1 \cdot 13^{\mathrm{b}}$ & 18.5 & $45.91^{d}$ \\
\hline Day $12 \cdot 0$ & 4 & $7 \cdot 6$ & $5 \cdot 4$ & $0 \cdot 13^{a}$ & $15 \cdot 1$ & $21 \cdot 2^{c}$ \\
\hline Overall s.e.m. & & \pm 0.96 & \pm 0.93 & $\pm 0 \cdot 178$ & \pm 1.87 & \pm 9.94 \\
\hline
\end{tabular}

Values with different superscripts are different at a, b $P<0.01$ and c, d $P<0.05$.

Data are means. 
3-6 mm in diameter. Content of protein in uterine flushings was similar in treatment groups; but administration of oestrogen on Day 10.5 increased total recoverable calcium $(P<0.01)$ and acid phosphatase activity $(P<0.05)$ in uterine flushings compared with vehicle-treated gilts and those treated with oestrogen on Day 12 (Table 1 ).

Treatment of gilts with oestrogen on Day 10.5 of pregnancy reduced the number of gilts containing embryos in the uterine horn removed on Day 23 of pregnancy $(P<0.02)$. None of the 5 gilts treated with oestrogen on Day 10.5 contained embryos on Day 23 compared with 5 of 7 $(71.4 \%)$ vehicle-treated gilts and 3 of $5(60.0 \%)$ gilts treated with oestrogen on Day 12 . All gilts administered oestrogen on Day 10.5 and 2 gilts injected on Day 12 of pregnancy appeared to be returning to oestrus on Day 23, as large corpora albicantia and developing follicles were present. The 2 nonpregnant control gilts returned to oestrus by Day 21. Numbers of CL and embryos on Day 23 were similar in vehicle-treated gilts $(6.8 \pm 1.0$ and $3.8 \pm 0.9)$ and those treated with oestrogen on Day $12(7 \cdot 0 \pm 1.6$ and $6.5 \pm 1 \cdot 5)$.

\section{Discussion}

Using our model of asynchronous embryo transfer and oestrogen treatment, the results of the present study suggest that there are 2 periods of uterine selectivity during early conceptus development in pigs. The first period of embryonic loss is not caused by competition among littermate embryos, but is related to asynchrony between development of the embryo and its uterine environment. Polge (1982) demonstrated that the success of establishing pregnancy with the transfer of advanced $(+24-48 \mathrm{~h}$ ) embryos was comparable to that obtained using embryos synchronous with the recipient's oestrous cycle. However, in contrast to embryo transfer results reported in sheep and cattle (see Wilmut et al., 1985), pregnancy rates decreased for embryos transferred $24 \mathrm{~h}$ behind and were negligible when transferred embryos were $\geqslant-48 \mathrm{~h}$ from synchrony with the recipient. Failure to establish pregnancy with embryos transferred $48 \mathrm{~h}$ behind the recipient's oestrous cycle is not related to trophoblastic elongation or synthesis of oestrogen as these embryos did not survive to Day 11 of pregnancy in Expt 1. Early loss was caused by rapid deterioration of the embryos within $24 \mathrm{~h}$ following transfer of Day-6 embryos to Day-8 recipients in Expt 2. Rapid deterioration of Day-4 embryos transferred into an advanced $(+48 \mathrm{~h})$ uterine environment has also been reported by Jarrell et al. (1990). Retransfer of Day-4 embryos into a synchronous recipient after a short-term ( $24 \mathrm{~h}$ ) exposure to an advanced (Day 6) uterine environment also resulted in a significant increase in degeneration and loss of embryos by Day 11 of pregnancy. Collectively, these data indicate that early embryonic survival is not inhibited when embryos are advanced compared with the recipient's uterine environment, but younger embryos are intolerant of an advanced uterine environment.

Our results suggest that a second period of uterine selectivity to embryonic development and survival occurs after the period of conceptus elongation and oestrogen synthesis between Days 11 and 12 of pregnancy. Results of Expt 2 indicated that, if asynchronous (transfer $24 \mathrm{~h}$ behind the recipient's oestrous cycle) embryos are present in the recipient uterus on Day 11, administration of oestrogen does not interfere with the ability of the conceptuses to undergo rapid trophoblast elongation, which is consistent with the results of Morgan et al. (1987b). Although the administration of oestrogen results in a systemic effect, treatment of gilts with oestradiol-17 $\beta$ on Day 11 stimulates a physiological response in uterine release of calcium, protein and uteroferrin as occurs during early pregnancy (Geisert et al., 1982).

Although results of previous studies indicated that oestrogen administration can inhibit conceptus attachment after Day 12 in pigs, stimulation of the uterus with oestrogen on Days 9 and 10 , as in the study of Morgan et al. (1987b), is not physiological. Induced release of uterine secretions by oestrogens synthesized by more-developed littermate embryos would only occur between Days 11 and 12 of pregnancy. The abnormal endometrial protein synthesis (Gries et al., 1989) and loss of the uterine epithelial glycocalyx (Blair et al., 1991) indicates that oestrogen administration on 
Days 9 and 10 is an inappropriate model for studies of embryonic mortality caused by the diversity in development of littermate embryos as proposed by Pope et al. (1990). Administration of oestrogen to pregnant gilts via i.v. injection (Expt 3) allowed us to stimulate a physiological release of intraluminal calcium and acid phosphatase activity within $8-12 \mathrm{~h}$, as reported for cyclic gilts by Young et al. (1987). Uterine environmental changes induced by oestrogen in Expt 3 occurred when the majority of gilts contained spherical blastocysts $4-5 \mathrm{~mm}$ in diameter. Therefore, uterine secretions were stimulated at least $20-30 \mathrm{~h}$ before conceptus trophoblastic elongation. Given the diversity in embryonic development that can occur during pregnancy (Wilmut et al., 1985; Pope et al., 1988) and the association of oestrogen synthesis with development within a litter (Pusateri et al., 1990), the advanced uterine secretions induced by oestrogen would mimic the timing of oestrogen secretion by embryos advanced in development and would not result in the abnormal development of the uterine epithelium observed when treated on Days 9 and 10. Results of Expt 3 indicate that advanced stimulation of uterine secretions on Day 11 results in total embryonic loss by Day 23. Although some animals treated with vehicle or with oestrogen on Day 12 did not maintain pregnancy after the initial surgery, the majority contained embryos on Day 23. Maintenance of pregnancy in gilts treated with oestrogen after conceptus elongation (Pope et al., 1986; present study) demonstrates that embryonic loss is a result not of exogenous oestrogen, but of the time at which it is administered. Previous results indicate that conceptus elongation is not affected by oestrogen treatment; therefore, early embryonic death could result from either inappropriate timing of uterine secretion (Morgan et al., 1987a) or the inability of the conceptus to attach to the uterine epithelial glycocalyx, which is stimulated by embryo oestrogen on Days 11-12 of pregnancy (Blair et al., 1991) or after administration of oestrogen (Keys \& King, 1988).

Results of the present study indicate that the uterus of pigs selects against embryos which are too asynchronous in development with the uterine environment after Day 8 of pregnancy. After Day 10, synthesis and release of oestrogen by more-advanced embryos may result in loss of less developed littermates after Day 12 of pregnancy. The effects of oestrogen stimulation on embryonic survival on Day 12 of pregnancy emphasize the importance of embryo uniformity in increasing litter size and embryonic survival rate, as occurs in Chinese Meishan pigs (Bazer et al., 1988).

Journal Article No. 5917 of Agricultural Experiment Station, Oklahoma State University, Stillwater. We thank R. Schmitt, L. O'Neill and P. Groothius for their technical assistance and S. Geisert for typing the manuscript. This research was supported by USDA Grant 86-CRCR-1-1875.

\section{References}

Barr, A.J., Goodnight, J.H., Sall, J.P., Blair, W.H. \& Chilko, D.M. (1979) General linear models procedure of the Statistical Analysis System. SAS User's Guide. Cary, NC: SAS Institute, Inc.

Blair, R.M., Geisert, R.D., Zavy, M.T., Yellin, T., Fulton, R.W. \& Short, E.C. (1991) Morphological and secretory alterations associated with embryonic mortality in gilts administered estradiol valerate on days 9 and 10 of gestation. Biol. Reprod. 44, 1063-1079.

Bazer, F.W., Vallet, J.L., Roberts, R.M., Sharp, D.C. \& Thatcher, W.W. (1986) Role of conceptus secretory products in establishment of pregnancy. $J$. Reprod. Fert. 76, 841-850.

Bazer, F.W., Thatcher, W.W., Martinat-Botte, F. \& Terqui, M. (1988) Conceptus development in large white and prolific Chinese Meishan pigs. J. Reprod. Fert. 84, 37-42.

Dhindsa, D.S. \& Dziuk, P.J. (1968) Effect of pregnancy in the pig after killing embryos or fetuses in one uterine horn in early gestation. J. Anim. Sci. 27, 122-126.
Frank, M., Bazer, F.W., Thatcher, W.W. \& Wilcox, C.J. (1978) A study of prostaglandin $F_{2 a}$ as the luteolysin in swine. IV. An explanation for the luteotrophic effect of estradiol. Prostaglandins 15, $151-160$.

Geisert, R.D., Renegar, R.H., Thatcher, W.W., Roberts, R.M. \& Bazer, F.W. (1992) Establishment of pregnancy in the pig. I. Interrelationships between preimplantation development of the pig blastocyst and uterine endometrial secretions. Biol. Reprod. 27, 925-939.

Geisert, R.D., Zavy, M.T., Wettemann, R.P. \& Biggers, B.G. (1987) Length of pseudopregnancy and pattern of uterine protein release as influenced by time and duration of oestrogen administration in the pig. $J$. Reprod. Fert. 79, 163-172.

Geisert, R.D., Zavy, M.T., Moffatt, R.J., Blair, R.M. \& Yellin, T. (1990) Embryonic steroids and the establishment of pregnancy in pigs. J. Reprod. Fert. Suppl. 40, 293-305. 
Gries, L.K., Geisert, R.D., Zavy, M.T., Garrett, J.E. \& Morgan, G.L. (1989) Uterine secretory alterations coincident with embryonic mortality in the gilt after exogenous estrogen administration. J. Anim. Sci. 67, 276-284.

Jarrell, V.L., Beckmann, L.S., Cantley, T.C., Rieke, A.R. \& Day, B.N. (1990) The effect of exposure to an asynchronous uterus on development of day 4 swine embryos. J. Anim. Sci. 68 (Suppl. 1), 429.

Keys, J.L. \& King, G.J. (1988) Effect of intraluminal application and systemic administration of estradiol $\left(\mathrm{E}_{2}\right)$ on porcine endometrial morphology. Biol. Reprod. 38 (Suppl. 1), 132.

Morgan, G.L., Geisert, R.D., Zavy, M.T., Shawley, R.V.\& Fazleabas, A.T. (1987a) Development of pig blastocysts in a uterine environment advanced by exogenous oestrogen. J. Reprod. Fert. 80, 125-131.

Morgan, G.L., Geisert, R.D., Zavy, M.T. \& Fazleabas, A.T. (1987b) Development and survival of pig blastocysts after estrogen administration on Day 9 or Days 9 and 10 of pregnancy. J. Reprod. Fert. 80, 133-141.

Polge, C. (1982) Embryo transplantation and preservation. In Control of Pig Reproduction, pp. 277-291. Eds D. J. A. Cole \& G. R. Foxcroft. Butterworth Scientific, London.

Pope, W.F. (1988) Uterine asynchrony: a cause of embryonic loss. Biol. Reprod. 39, 999-1003.

Pope, W.F. \& First, N.L. (1985) Factors affecting the survival of pig embryos. Theriogenology 23, 91-105.

Pope, W.F., Maurer, R.R. \& Stormshak, F. (1982) Survival of porcine embryos after asynchronous transfer. Proc. Soc. exp. Biol. Med. 171, 179-183.

Pope, W.F., Lawyer, M.J., Butler, W.R., Foote, R.H. \& First, W.L. (1986) Dose-response shift in the ability of gilts to remain pregnant following exogenous estradiol-17ß exposure. J. Anim. Sci. 63, 1208-1210.
Pope, W.F., Wilde, M.H. \& Xie, S. (1988) Effect of electrocautery of nonovulated Day 1 follicles on subsequent morphology variation among Day 11 porcine blastocysts. Biol. Reprod. 39, 882-887.

Pope, W.F., Broermann, D.M. \& Nephew, K.P. (1990) Causes and consequences of early embryonic diversity. J. Reprod. Fert. Suppl. 40, 250-260.

Pusateri, A.E., Rothschild, M.F., Warner, C.M. \& Ford, S.P. (1990) Changes in morphology, cell number, cell size and cellular estrogen content of individual littermate pig conceptuses on Days 9 to 13 of gestation. $J$. Anim. Sci. 68, 3727-3735.

van der Meulen, J., Helmond, F.A. \& Oudenaarden, C.P.J. (1988) Effect of flushing of blastocysts on Days 10-13 on the lifespan of the corpora lutea in the pig. J. Reprod. Fert. 84, 157-162.

Wilmut, I., Sales, D.I. \& Ashworth, C.J. (1985) The influence of variation in embryo stage and maternal hormone profiles on embryo survival in farm animals. Theriogenology 23, 107-119.

Wu, M.C., Chen, Z.Y., Jarrell, V.L. \& Dziuk, P.J. (1989) Effect of initial length of uterus per embryo on fetal survival and development in the pig. J. Anim. Sci. 67, 1767-1772.

Xie, S., Broermann, D.M., Nephew, K.P., Geisert, R.D. \& Pope, W.F. (1990) Ovulation and early embryogenesis in swine. Biol. Reprod. 43, 236-270.

Young, K.H., Bazer, F.W., Simpkins, J.W. \& Roberts, R.M. (1987) Effects of early pregnancy and acute 17 $\beta$ estradiol administration on porcine uterine secretion, cyclic nucleotides, and catecholamines. Endocrinology 120, 254-263.

Received 10 December 1990 